\title{
Diagnóstico da gestão cultural em Instituições de Ensino Superior Públicas Brasileiras
}

Paulo Nunes ${ }^{1}$

\section{Resumo}

Como estão estabelecidas as ações culturais dentro das Instituições de Ensino Superior (IES) públicas no Brasil, e quais as principais características dos seus modelos de gestão cultural? Buscando responder a estas questões, o artigo em tela condensa os principais resultados de um estudo conduzido em 2017, com a participação de $33,4 \%$ do número total IES públicas do país. A partir do emprego de uma ficha de coleta de dados com questões, abertas e fechadas, os resultados das 99 respostas recebidas estão organizados em três diferentes seções, que buscam discutir: (i) os lugares e desafios da cultura na universidade: (ii) a caracterização geral das atividades culturais desenvolvidas nas instituições participantes da investigação e (iii) os diferentes modelos de gestão cultural nas IES públicas nacionais. De modo geral, é possível afirmar que o modelo de gestão cultural no Brasil é bastante heterogêneo e carece de políticas públicas, ferramentas técnicas e medidas administrativas mais coerentes, estáveis e que facilitem seu campo de atuação.

\section{Palavras-chave}

Cultura. Atividades culturais. Universidade. Gestão cultural. Extensão universitária.

\footnotetext{
${ }^{1}$ Doutor em Sociologia, Cidades e Culturas Urbanas pela Universidade de Coimbra, Portugal; professor assistente no Instituto de Ciências da Universidade Federal de Itajubá, Minas Gerais, Brasil. E-mail: paulonunes.unifei@gmail.com.
} 


\title{
Diagnosis of cultural management in Brazilian Public Higher Education Institutions
}

Paulo Nunes $^{2}$

\begin{abstract}
How cultural practices are established in Public Higher Education Institutions in Brazil, and what are the main characteristics of their cultural management models? Seeking to answer these questions, this paper condenses the main results of a study conducted in 2017, with the participation of $33.4 \%$ of the total number of this kind of institution in the country. From the use of a inquiry with open and closed questions, the results of the 99 responses received are organized into three different sections, which seek to discuss: (i) the places and challenges of culture in the university: (ii) the general characterization of cultural activities developed in the institutions participating in the research and (iii) the different models of cultural management in national public HEIs. In general, it is possible to state that the Brasilian cultural management model is quite heterogeneous and has lacks of public policies, technical tools and administrative measures more coherent, stable and that can facilitate their field of action.
\end{abstract}

\section{Keywords}

Culture. Cultural activities. University. Cultural management. University extension.

\footnotetext{
${ }^{2} \mathrm{PhD}$ in Sociology, Cities and Urban Cultures, University of Coimbra, Portugal; assistant professor at the Institute of Sciences at the Federal University of Itajubá, State of Minas Gerais, Brazil. E-mail: paulonunes.unifei@gmail.com.
} 


\section{Introdução}

Segundo os dados do último resumo técnico do Instituto Nacional de Estudos e Pesquisa Anísio Teixeira (INEP), feito em 2017, o Brasil conta com um total de 2.448 Instituições de Ensino Superior (IES) espalhadas em todo o território nacional. Destas, 296 $(12,1 \%)$ são de categoria administrativa pública e responsáveis pelo oferecimento de 793.948 vagas em cursos de graduação (LORENZONI, 2017).

Em linhas gerais, o crescimento do ensino superior no país enfrenta os desafios da democratização do acesso, da articulação com as outras etapas da formação escolar e do provimento de educação com qualidade ligada com os demais setores da sociedade, incluindose aí o campo cultural. Os debates acerca do papel social da universidade, da valorização das práticas extensionistas e da presença do Estado na gestão da educação, proteção e fomento dos bens culturais têm indicado a necessidade de um desenvolvimento contínuo de políticas específicas para as IES brasileiras. A cultura ocupa um papel decisivo nesta dinâmica, uma vez que se constitui de um processo de apropriação que permite ao sujeito a construção de si próprio, de ser a matriz, de ter o controle e estratégias da constituição de seu papel como agente transformador da realidade (CAUNE, 2012).

De maneira um tanto quanto controversa, o ensino superior no país, historicamente, tem tido como objetivo prioritário a formação de recursos humanos para o mercado de trabalho. A profissionalização dos jovens assumida por essas instituições era - e ainda hoje o é demasiadamente focada nas atividades em sala de aula, colocando, muitas vezes, o aluno como sujeito passivo no processo de ensino. A formação cidadã, quando realizada, acaba acontecendo em segundo plano, presente apenas em disciplinas optativas, ou mesmo na ação isolada de alguns professores ou cursos (NUNES JUNIOR et al., 2016). Por esta razão, diferentes políticas governamentais implementadas pelos governos Lula e Dilma, entre 2003 e 2016, somadas às diretrizes formuladas em cada uma das diversas IES espalhadas pelo país, buscaram incrementar a participação de professores, técnicos administrativos e estudantes em projetos culturais visando a construção de programas coletivos e integradores dentro do campo cultural.

Devido a sua eloquência cada vez mais importante como veículo de ação, controle e transformação social, a cultura tem ocupado lugar central nas políticas intersetoriais como um todo e nas políticas relacionadas à educação de uma maneira mais particular, tal como sugerem os estudos de Barnabé (2012). Por esta razão, desde a década de 1970, a Organização das Nações Unidas para a Educação, a Ciência e a Cultura (Unesco) tem proposto um novo 
viés para o ensino superior, enfatizando a cultura como elemento importante de formação de identidade e de diminuição de desigualdades para os indivíduos e as nações (SPELLER et al., 2012). Nesta visão, o ensino superior é entendido como sendo a etapa de reafirmação dos conceitos humanísticos adquiridos pelos indivíduos ao longo de sua formação.

No caso brasileiro, chama a atenção a forte vertente da gestão cultural aliada às políticas públicas de pensamento democrático, tal como demonstrado pelas prerrogativas do trabalho de Barros (2008). Segundo o autor, "o pluralismo cultural é propício aos intercâmbios culturais e ao desenvolvimento das capacidades criadoras que alimentam a vida pública" (BARROS, 2008, p. 1). Para Rubim (2013), o desafio de construir políticas de cultura em um ambiente democrático é enfrentado por meio do acionamento da sociedade civil e dos agentes culturais na conformação de políticas públicas e democráticas de cultura.

Além de ser tratada como linha temática da extensão universitária nacional, o tema da gestão cultural no ensino superior público do país torna-se importante se considerarmos que, nesta última década, houve um aumento bastante significativo no número total de alunos ingressantes nos cursos de graduação brasileiros. O maior impulso ocorreu em instituições públicas, onde houve um crescimento de 7,9\%, somando-se, até a data do último censo educacional, um total de 6.739.689 pessoas matriculadas (LORENZONI, 2017).

Tendo por base esse público, inúmeras são as formas assumidas pelas IES públicas brasileiras para a atuação na área da cultura. Entre as principais podemos citar o reconhecimento e a difusão da pluralidade cultural produzida na universidade e na sociedade; o diagnóstico e o mapeamento de informações e indicativos culturais; os estudos e pesquisas para a construção de políticas públicas e, principalmente, a oferta e a divulgação de ações culturais desenvolvidas dentro da própria instituição.

Entretanto, pouco ainda tem-se discutido em relação a modelos de gestão e políticas culturais específicas para o setor universitário, e esta foi a principal justificativa que motivou o desenvolvimento da pesquisa em tela durante o ano de 2017. Escrito originalmente em espanhol e sob a forma de relatório técnico para a Universidad de Cádiz e Universidad Internacional de Andalucía (NUNES JUNIOR, 2017), o estudo que aqui será apresentado traz elementos quantitativos e qualitativos inéditos e importantes para a discussão do tema no cenário nacional. Por esta razão, se achou pertinente que os resultados fossem publicados também em língua portuguesa, em diálogo direto com o contexto brasileiro e com a extensão universitária. 
Como estão estabelecidas as ações culturais dentro das IES públicas nacionais e quais as principais características dos seus modelos de gestão cultural? Estas duas questões conduziram a realização do estudo e suscitaram diálogos com textos e artigos científicos relacionados às políticas culturais para o ensino superior de uma forma mais geral (LONDOÑO; GONZÁLEZ, 2006; COSTA et al., 2009; GONZÁLEZ, 2013) e, de um modo mais particular, para o caso brasileiro (BARNABÉ, 2012; CERRETI, 2014; ARRUDA, 2017; GOMES, 2017).

Os resultados estão organizados a partir de três diferentes aspectos, buscando suscitar, primeiramente, os lugares e desafios da cultura na universidade para, em seguida, apresentar uma caracterização geral das atividades culturais desenvolvidas nas instituições participantes da investigação. Por último, são estabelecidos apontamentos gerais sobre diferentes modelos de gestão cultural nas IES públicas nacionais. Espera-se que as informações apresentadas neste artigo auxiliem na avaliação de processos administrativos, permitindo recriá-los a partir de uma lógica que estabeleça a cultura como canal emancipador de sujeitos e promotor da interação transformadora da Universidade com os demais setores da sociedade (FORPROEX, 2012).

\section{Metodologia e dados gerais das instituições pesquisadas}

Além das atividades de revisão bibliográfica, o estudo foi conduzido a partir do emprego de uma ficha de coleta de dados que contou com 33 questões, abertas e fechadas, divididas em oito blocos temáticos: (i) modelos de gestão; (ii) instrumentos de deliberação institucionais; (iii) políticas de participação; (iv) descentralização de recursos; (v) organograma e/ou divisões administrativas; (vi) áreas culturais abrangidas, (vii) perfis de projetos e públicos alvo; (viii) histórico e propensões ao trabalho em rede.

Essa ficha de coleta de dados foi divulgada por correio eletrônico pela assessoria contratada para a execução da pesquisa. A lista de destinatários foi criada a partir dos contatos concedidos por redes de colaboração de pesquisadores na área da gestão cultural universitária no Brasil e pelo levantamento dos canais de comunicação institucionais oficiais das IES públicas nacionais. As informações de contato foram organizadas em sete diferentes seções: nome do gestor, nome da instituição de ensino superior, sigla, Estado, website, telefone institucional e email profissional. A compilação desses dados e a criação de lista de instituições participantes da pesquisa tomou por referência a base de dados do censo do 
Instituto Nacional de Estudos e Pesquisas Educacionais Anísio Teixeira, na qual estão contabilizadas no território brasileiro um total de 296 IES na esfera pública (INEP, 2017).

O questionário foi enviado para os gestores e os departamentos responsáveis pela pasta da cultura nas IES públicas brasileiras. Os contatos foram feitos em duas rodadas: uma primeira, via correio eletrônico e, uma segunda, via telefone. Embora as perguntas fossem diretas, de fácil interpretação e, em sua maioria, fechadas, o prazo para o recebimento das respostas precisou ser prorrogado por duas vezes em razão da baixa devolutiva de respostas. Outras medidas de divulgação incrementaram o potencial de alcance e retorno da pesquisa, a exemplo de postagens criadas em redes sociais e fóruns online ligados ao tema, de envio de emails personalizados a gestores e instituições específicas, além de ações de divulgação internas promovidas pelo Fórum de Pró-Reitores de Extensão das Insituições Públicas de Educação Superior Brasileiras (FORPROEX).

Ao final dos três meses de coleta de dados (julho a setembro de 2017) foram obtidas um total de 99 respostas válidas, ou seja, 33,4\% do universo de 296 IES públicas existentes no país. Tal resultado constituiu-se como amostra bastante significativa para este campo de estudos, principalmente se considerarmos a quantidade de unidades administrativas e respectivas cidades sede abrangidas por cada IES. De acordo com os dados recebidos, 28,8\% delas apresentam 10 ou mais campi universitários, $12,5 \%$ têm entre 7 e 10, 12,5\% entre 6 e 7 e outras $26 \%$ têm entre 4 e 5 unidades administrativas. A este fato somam-se ainda as categorias institucionais que compõem o espectro de respostas (70,2\% das IES respondentes são Universidades), 23,1\% Institutos Federais de Educação, Ciência e Tecnologia, 3,8\% Faculdades e 1,9\% Centros Universitários) e suas diferentes escalas de governança (70,2\% das IES estão sob administração federal, 24\% sob a administração estadual e 4,8\% sob administração municipal).

As respostas são oriundas de 21 diferentes estados brasileiros. São Paulo foi o lugar de origem do maior número delas (15), seguido de Minas Gerais (12), Rio Grande do Sul (9) e Bahia (8). Em linhas gerais, e de acordo com os dados oficiais sobre o ensino superior nacional (LORENZONI, 2017), a quantidade de respostas recebidas foi, em média, proporcional ao número de IES presentes em cada Estado (INEP, 2017), perfazendo uma grelha de valor significativo para os estudos sobre gestão cultural no país. 


\section{Resultados e Discussão}

\section{Lugares e desafios da Cultura na Universidade}

Por construir raízes dentro de um sistema de governança militar, o percurso das políticas públicas de cultura no Brasil demorou para ganhar institucionalidade e acúmulo de diálogos mais democráticos (BOTELHO, 2011). Ocupando lugar nas políticas setoriais da educação a partir da década de 1960, a cultura acabou por mostrar-se através de ações específicas dentro das universidades. Tomada como temática festiva e iconoclasta do folclore brasileiro, desde então ela tem se manifestado, na maioria das vezes, em associação a eventos pontuais organizados para cumprir o calendário cívico tradicional.

No que tange ao assunto da gestão do tema nas universidades, um dos marcos mais significativos foi a criação da Fundação Nacional de Artes (FUNARTE) em 1975. Desde sua constituição, havia inúmeras requisições advindas das universidades com solicitações de apoio às suas atividades culturais, para as quais o MEC, normalmente, não designava recursos (BOTELHO, 2011). Estas demandas foram reunidas no chamado Projeto Universidade, criado em 1981, o qual trabalhava basicamente com a área de extensão cultural das universidades, “com o objetivo de auxiliá-las a se tornarem pólos irradiadores de cultura para a comunidade, por meio da promoção de atividades artísticas não eventuais” (BOTELHO, 2011, p. 99).

A partir daí, a elaboração das políticas públicas de cultura foi marcada pela construção de seus conceitos e diretrizes dentro do então Ministério da Educação e Saúde e, posteriormente, com a criação do Ministério da Cultura, em 1985, quando ocorreu a aproximação destas políticas com a pasta da educação (RUBIM, 2007). Esse foi o caso do Edital Proext (2003), para o financiamento da arte e da cultura como projetos de extensão universitária, e da criação do Programa Mais Cultura nas Universidades ${ }^{3}$ (2014), ambos assinados pelo Ministério da Educação em parceria com o Ministério da Cultura e outras pastas do poder executivo.

Embora 84,6\% delas estejam alocadas sob o grande guarda chuva das atividades de extensão dentro das universidades, tal como sugere o gráfico da Figura 1, não existe consenso entre os estudiosos e gestores da área de que esse seja, de fato, o melhor lugar para as expressões concernentes a este campo se desenvolverem (GOMES, 2017).

\footnotetext{
${ }^{3}$ É importante enfatizar que, nos últimos anos, os dois editais foram extintos, tal como uma série de outras políticas públicas voltadas para o fomento da cultura em aproximação com a área da educação.
} 
Figura 1 - Organização da gestão cultural nas IES

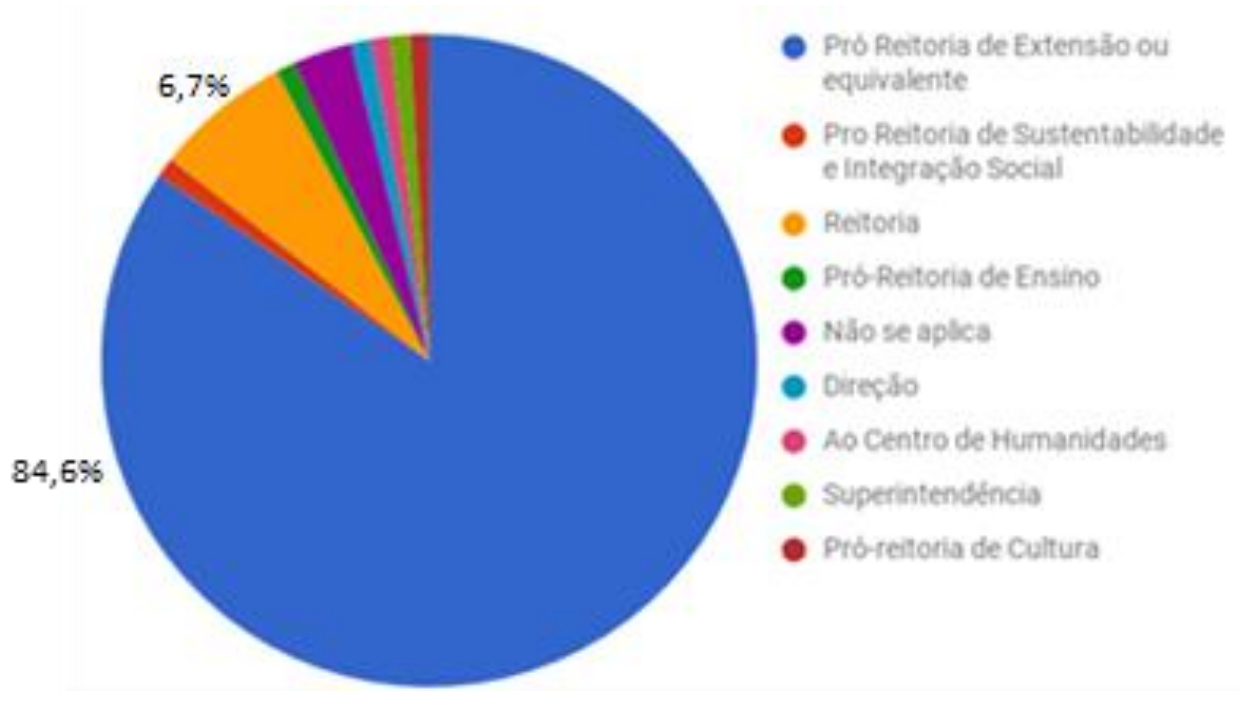

Fonte: O autor (2019).

O gráfico exposto na Figura 1 indica que 88 das 99 instituições respondentes $(84,6 \%$ do total) têm sua gestão cultural sob a alçada de uma Pró-Reitoria de Extensão ou órgão equivalente, geralmente responsável pela criação de projetos que aproximam a universidade e a sociedade como um todo. Além das respostas residuais, apenas 6,7\% das IES têm a seção ligada diretamente à Reitoria de suas respectivas universidades.

Do ponto de vista de orçamento e distribuição de recursos, mesmo contando com editais próprios e políticas de financiamento interministeriais específicas, a concepção e execução de projetos práticos na área cultural muitas vezes esbarra no próprio diálogo primário existente com o campo da educação, e "não se trata de uma particularidade brasileira: na maioria dos países, mesmo nos desenvolvidos, o relacionamento entre as duas pastas é difícil e cheio de percalços” (BOTELHO, 2011, p. 97).

De acordo com as respostas abertas recebidas dos gestores, à lista de desafios que pode constituir um campo de ação eficiente e perene para a cultura no ensino superior público brasileiro soma-se, por exemplo, a falta de formação específica na área, o financiamento flutuante, a ineficiência na comunicação entre as instituições de ensino das diferentes regiões do país, a falta de materiais técnicos de produção cultural, a carência de infraestruturas e espaços físicos apropriados para eventos e, em linhas mais gerais, o entendimento controverso de que a cultura deve servir como "acessório" para atividades de demonstração em eventos acadêmicos. Segundo Botelho (2011, p. 99), a pasta ficou "relegada a uma condição 
secundária nos programas e currículos de educação formal, na medida em que se privilegiam valores culturais alheios ao contexto específico em que se dá a formação do indivíduo".

A estrutura organizacional e administrativa das grandes universidades brasileiras contrasta com o baixo número de profissionais designados para o setor na maioria das IES públicas, evidenciando as desigualdades enfrentadas pela gestão cultural no cenário do país. De acordo com as informações cedidas pela IES participantes da pesquisa, nas suas seções específicas voltadas para a gestão da cultura, existe a presença média de apenas um ou dois funcionários alocados nas funções do setor dentro das universidades (15,5\% e 20,4\%, respectivamente), em contraposição aos outros 22,3\% da média nacional, que têm 10 ou mais empregados na pasta. A disparidade desses números pode guardar relação com a quantidade de alunos matriculados e unidades administrativas (campi fora de sede) de cada instituição. No entanto, em geral, as instituições nas quais a gestão cultural aparece de forma consolidada (com maior número de funcionários lotados no setor e espaços deliberativos específicos para a discussão de políticas setoriais, por exemplo) são aquelas que apresentam maior capacidade de oferecimento de atividades, projetos e programas na área cultural.

\section{Caracterização das ações culturais}

O delineamento das principais áreas temáticas abrangidas pelos projetos institucionais é informado pela Figura 2. Neste gráfico podemos observar o Canto Coral e o Teatro como as práticas mais recorrentes, ambos citados por 76,9\% das IES participantes da pesquisa. A Dança aparece em terceiro lugar, em 74\% dos casos, seguida pela Fotografia/Artes Visuais (72,1\%), Música Popular (69,2\%), Literatura (66,3\%), Cinema e Educação/Educação Popular/Patrimonial (ambos com 61,5\%), Música Instrumental/Erudita (60,6\%), Folclore/Cultura Popular (58,7\%) e Museus/Patrimônio Histórico (56,7\%). Como expressões artísticas menos recorrentes no universo dos projetos culturais das universidades aparecem o Circo $(13,5 \%)$ e atividades relacionadas à Moda $(1,9 \%)$. 
Figura 2 - Áreas culturais abrangidas pelos projetos de extensão institucionais

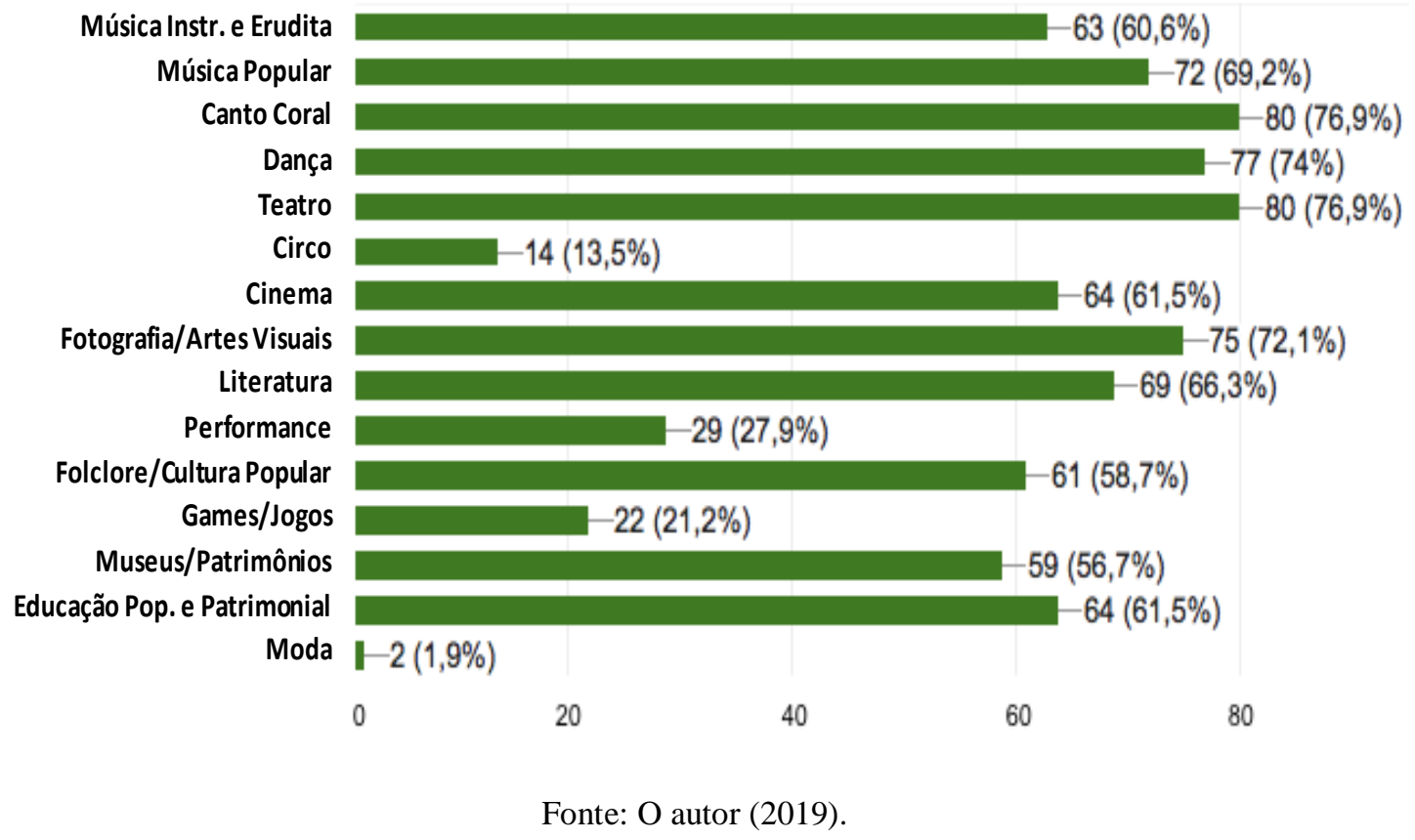

Tais dados são bastante pertinentes para uma caracterização geral do campo de ação da gestão cultural dentro das universidades. Além das informações expressas na Figura 2, foi possível extrair da grelha de respostas brutas que serviu de completo à pesquisa um total de 4.618 projetos e programas na área cultural, número gerador de uma média anual aproximada de 48,6 projetos por IES respondente.

A Figura 3 mostra as áreas temáticas de cursos graduação, pós-graduação e especialização oferecidas pelas IES no campo da cultura. A área da Fotografia/Artes Visuais aparece em primeiro lugar, citada por 44,2\% dos respondentes, a seguir vem a Música Instrumental (36,5\%), o Teatro/Circo (32,7\%), a Dança e Folclore/Estudos Culturais (ambos com 22,1\%), a Museologia/Patrimônio (21,2\%), o Cinema (19,2\%) e a Gestão/Produção Cultural (18,3\%). A questão não se aplicou a 34,6\% dos respondentes, possivelmente por não contarem com cursos na área em suas respectivas instituições. 
Figura 3 - Áreas temáticas dos cursos de graduação, pós-graduação e especialização

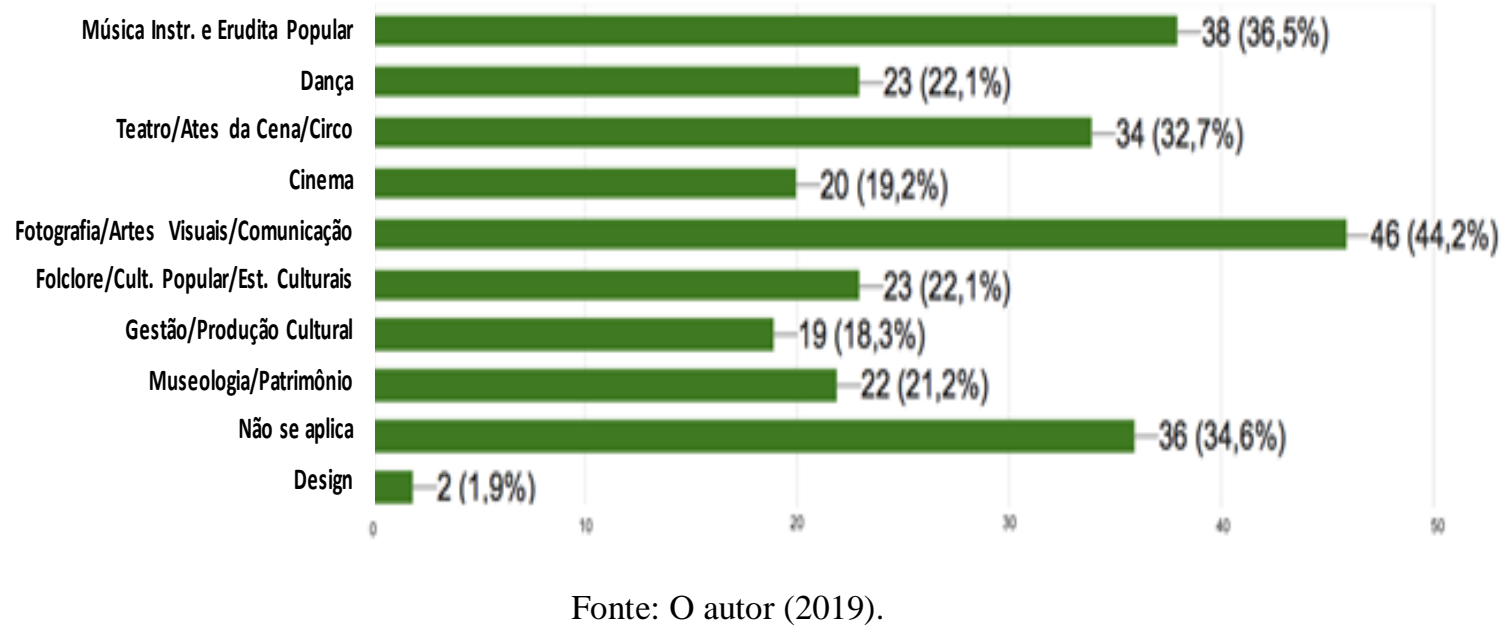

Embora não seja regra, o número de ações na área cultural pode ser maior em instituições que apresentam também cursos acadêmicos na área das artes, conforme é possível inferirmos, por exemplo, da alta relação entre cursos e projetos na área da Fotografia/Artes Visuais (44,2\% e 72,1\%, respectivamente) e da Música Instrumental/Erudita/Popular (36,5\% e 60,6\%, respectivamente). Em contrapartida, há exceções significativas nesta equação, como é o caso dos projetos na área do Canto Coral: eles estão presentes em 76,9\% das instituições, sendo que apenas $36,5 \%$ delas declararam cursos na área da música. $\mathrm{O}$ alto impacto das ações culturais promovidas pelas IES fica mais claro quando observamos a Figura 4:

Figura 4 - Público médio total anual atendido em projetos culturais (2017)

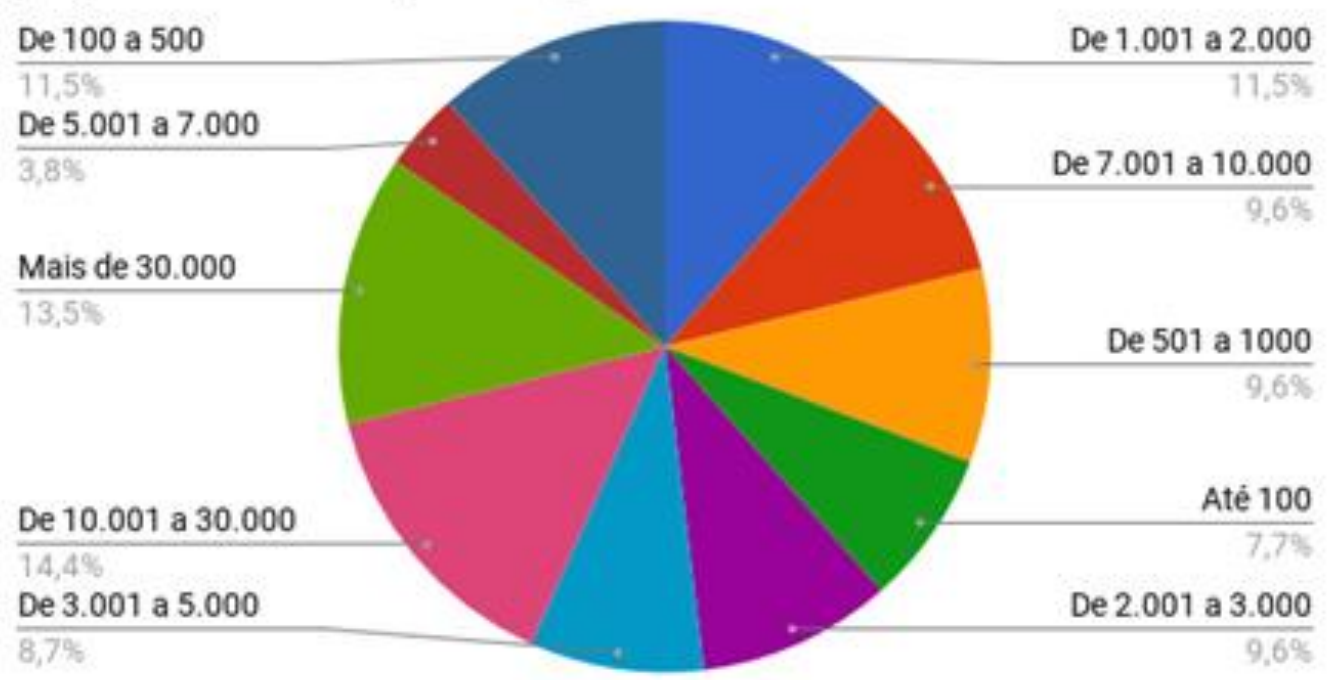

Fonte: O autor (2019). 
O gráfico apresenta o número médio total anual aproximado de público atendido pelos projetos na área nas instituições participantes da pesquisa. Nele, parcelas significativas dos respondentes assinalaram as opções com maior alcance: 13,5\% das instituições afirmaram atender mais de 30.000 pessoas por ano, seguidas de outras 14,4\% com atendimento médio entre 10.000 e 30.000 pessoas por ano. Esses valores expressam a abrangência significativa de públicos da cultura, no Brasil, intermediada pelas universidades. Mesmo, muitas vezes, à revelia de reconhecimento público e estatal, tais instituições são importantes protagonistas no acesso às ações e fazeres culturais ao redor do país.

\section{Desenhos de Gestão}

Sob o prisma da gestão, a cultura precisa ser entendida como campo multifacetado, e por isso mesmo, tem-se convertido em um tema desafiador para quaisquer sistemas administrativos, sejam eles provenientes de instituições universitárias ou não. Segundo o pensador Nestor García Canclini (apud LÓPEZ BORBON, 2015), quando falamos em gestão cultural é preciso termos claro que a multiplicidade de abordagens sobre seu objeto ultrapassa os alcances, as metodologias e os fins que os orientam.

Ao colocarmos essas prerrogativas em perspectiva com o gráfico da Figura 5, temos uma visão mais clara das questões para as quais o desafio de pensar em modelos de gestão nos remete. Mesmo constituindo-se como instituições de natureza pública, mais da metade das universidades brasileiras $(54,8 \%)$ não trabalham com espaços deliberativos específicos para a tomada de decisões sobre políticas de gestão cultural. Comissões e grupos de trabalho temáticos lideram a tipologia de espaços específicos para os outros $45,2 \%$ das IES que acenaram positivamente para esta questão, sendo esse o espaço de discussão privilegiado presente em 17 delas (34\% do total). Conselhos e câmaras, notadamente reconhecidos como lugares institucionais de discussão mais perene sobre políticas e diretrizes de ação institucionais no país, aparecem apenas em segundo e terceiro lugar: 28\% (14 casos) e 18\% (9 casos) das IES, respectivamente. 
Figura 5 - Tipologia de grupos e espaços deliberativos dentro das IES

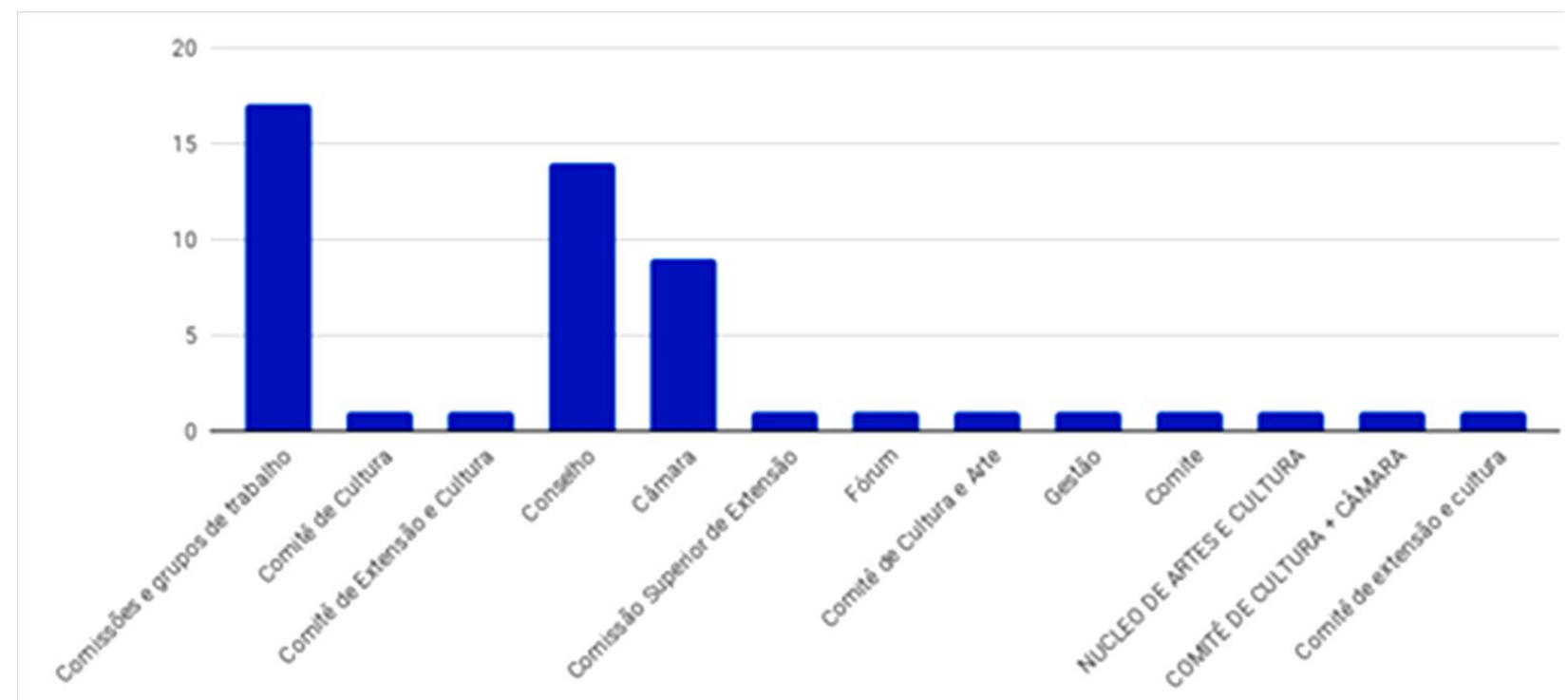

Fonte: O autor (2019).

Isso significa que muitas das frentes de trabalho que podem ser acionadas entre cultura e universidade, possivelmente, ficam aquém das multiplicidades possíveis para este campo. A carência de espaços deliberativos coletivos, nessas instituições, acabam por deixar de lado especificidades sobre grupos, demandas, prioridades sociais, rubricas orçamentárias e outros itens que, facilmente, podem passar despercebidos quando questionados por sujeitos que não têm o envolvimento direto e conhecimento tácito da práxis cultural.

O tema da gestão de recursos financeiros aplicada à cultura está mencionado na Figura 6.

Figura 6 - Mecanismos utilizados para descentralização de recursos orçamentários

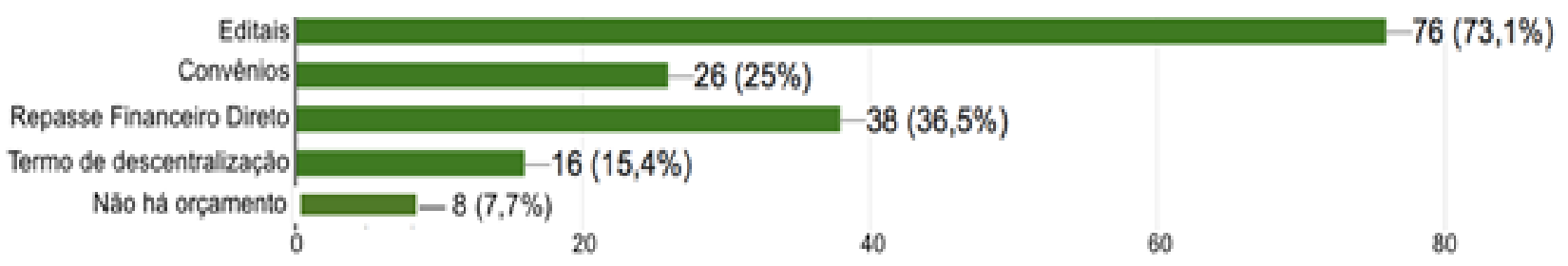

Fonte: O autor (2019). 
Ela apresenta dados referentes aos mecanismos de utilização de recursos empregados pelas IES, segundo o princípio da autonomia universitária vigente no Brasil. $73,1 \%$ delas mencionaram a utilização de editais públicos como ferramenta para este fim. Uma segunda parcela $(36,5 \%)$ acenou para o uso de repasse financeiro direto e outra cota $(25 \%)$ afirmou fazê-lo por meio de convênios. A respeito desta questão, chama a atenção ainda o fato de que, até $2017,7,7 \%$ das IES não apresentavam orçamento para a área da cultura.

Tal situação ajuda a denunciar a ausência de projetos extracurriculares e ações sóciopolíticas na universidade brasileira voltadas para a cultura, mesmo esta sendo uma das linhas temáticas básicas da política nacional de extensão universitária (FORPROEX, 2012). O contato com as experiências culturais são fundamentais para a formação do aluno, na medida em que, como já anunciado anteriormente, trata-se de um elemento importante de formação de identidade e de diminuição de desigualdades (SPELLER et al., 2012). Com o agravo, nos últimos anos, da crise financeira e econômica no país; com a extinção do Ministério da Cultura em 2019 e, cumulativamente, com a pandemia sanitária provocada pelo coronavírus em 2020, certamente o orçamento destinado à cultura para as IES brasileiras diminuiu ainda mais, tornando urgente a discussão sobre orçamento e repasse de recursos para ações e projetos culturais.

A Figura 7 mostra os mecanismos utilizados para captação de recursos extraorçamentários na complementação do financiamento da pasta da cultura em cada uma das IES.

Figura 7 - Mecanismos utilizados para captação de recursos extra orçamentários

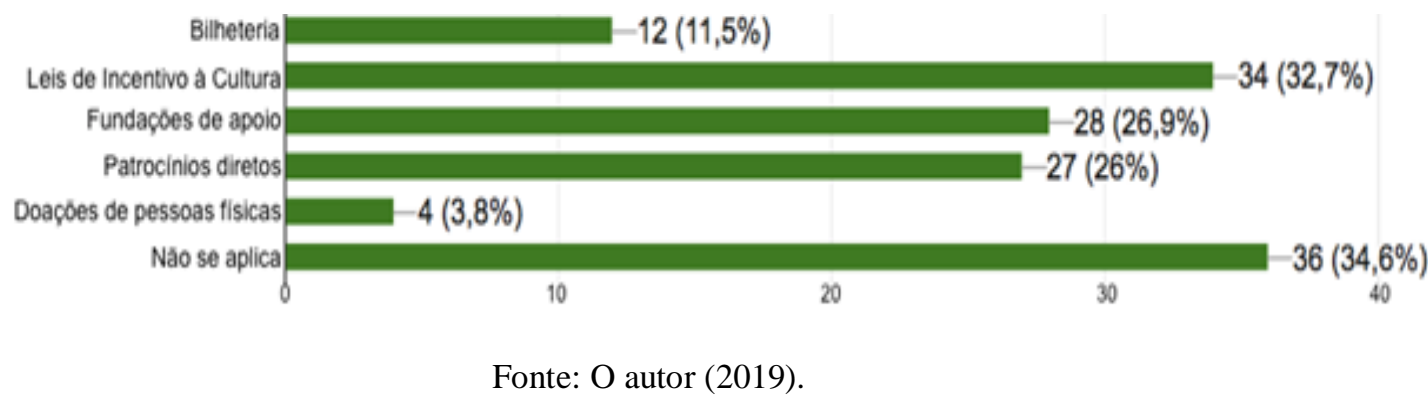

Os 34,6\% dos respondentes que assinalaram a opção "Não se aplica" provavelmente não se servem de recursos externos à instituição para a promoção de suas ações culturais. Isso pode indicar que este um terço de respondentes utiliza-se integralmente de planejamento orçamentário próprio para os gastos com cultura, mesmo com todas as fragilidades implicadas 
nesta ação. Em contrapartida, outros 32,7\% das IES declararam utilizar das Leis de Incentivo à Cultura (mecanismo de mecenato via isenção fiscal) para executar seus projetos, enquanto 26,9\% delas captam recursos a partir de suas Fundações de Apoio e outros 26\% o fazem a partir de patrocínios diretos. A arrecadação via bilheteria e/ou eventos culturais está presente em 11,5\% das IES, apresentando-se também como possível saída para a complementação de recursos da pasta, tendo em vista que, na grande maioria dos casos, o orçamento para a área da cultura está bastante aquém do desejado, ou costuma sofrer cortes internos não planejados no decorrer das atividades do ano fiscal. É importante mencionar, ainda, que recursos solicitados às agências de fomento à pesquisa não entraram nas respostas para este gráfico, tendo em vista que os mesmos são geridos pelas Pró-Reitorias de Pesquisa e seções equivalentes, ou seja, utilizados estritamente para projetos de investigação.

De acordo com Gomes (2017), deve-se considerar que, em muitos casos, o aparecimento do termo cultura junto ao nome do órgão não implica um investimento maior que o de outros que não assimilaram tal exposição terminológica. Embora o lugar administrativo institucional ocupado pela cultura seja uma variante importante dentro das universidades, ela não é necessariamente decisiva para a definição de um modelo de gestão eficaz e concatenado com as redes de comunicação internas e externas à instituição.

Além disso, apesar de estarem sob a égide de um mesmo sistema federativo, as IES públicas no Brasil possuem cada uma delas sistemas de administração bastante próprios, tendo em vista o princípio da autonomia universitária que as baliza. Tomando-se isso por pressuposto e em contato com a multiplicidade dos quadros organizacionais e organogramas que podem representar as 296 IES distribuídas em todo o Brasil, não é difícil pensar que a gestão cultural pode variar substancialmente de um lugar para outro. Seguindo o princípio da autonomia universitária vigente em nosso país, cada IES valoriza a cultura de forma independente, e em acordo com demandas específicas. Mesmo com algumas controvérsias, não há uma diretriz transversal do Ministério da Educação, do governo federal ou das agências de fomento que rejam as políticas culturais, uma vez que ela poderia surtir efeito homogeneizador nas práticas culturais nas diferenças multiculturais e nos regionalismos existentes ao redor do país.

Ao contrário de funcionarem como barreiras, essas diferenças podem potencializar as ações para possíveis trabalhos em rede e não precisam ser tomadas necessariamente como um problema. Barros (2008, p. 5) endossa este argumento quando sugere que "a gestão da diversidade cultural pode ser pensada como estratégia de negócios que transforma um problema, a presença dos diferentes desiguais, em oportunidades". Tais diferenças podem ser 
transformadas de potenciais conflitos em oportunidades produtivas e, por isso, a gestão cultural no Brasil precisa ser pensada a partir das possibilidades de articulação entre as IES.

\section{Conclusões}

Diante do exposto, é possível reafirmar que as universidades têm hoje papel significativo para o fomento da vida cultural e criação de políticas públicas no Brasil. As 99 respostas válidas recebidas (33,4\% do número total de IES públicas no país) constituem-se como amostra de campo bastante significativa, principalmente se considerarmos que a gestão cultural universitária tem sido um tema cada vez mais recorrente no cenário nacional e internacional.

Após a execução desta pesquisa, é possível dizer que, embora o campo da gestão cultural ainda apresente fragilidades e desafios a serem transpostos, como é o caso da organização de apenas $21,2 \%$ das IES com estrutura de Diretoria e a alta desigualdade em comparação ao número de funcionários lotados no setor, por exemplo, seu respaldo institucional vem crescendo e tornando-se mais visível por meio do grande número de projetos implementados e do público atingido durante o período investigado.

Perfazendo uma avaliação geral, é possível afirmar que o modelo de gestão cultural no país é bastante heterogêneo e carece de políticas públicas, ferramentas técnicas e medidas administrativas mais coerentes, estáveis e que facilitem seu campo de atuação. Tendo em vista as lacunas existentes na proposição de ações culturais como constituintes importantes do processo ensino-aprendizagem em grande parte das IES públicas brasileiras, os dados apresentados constituem-se como marco importante na direção apontada pelas diretrizes de educação e políticas culturais de nosso país.

Informações complementares da pesquisa realizada, e que não foram enquadradas na análise deste artigo, mostraram, ainda, que existe um potencial de articulação entre produção e oferta de ações culturais desenvolvidas em âmbito universitário no Brasil que ainda é subaproveitado e que pode ser dinamizado na possibilidade das universidades incrementarem iniciativas nesse campo.

Embora a cultura nas universidades não deva ser limitada apenas à extensão universitária, é por meio deste campo de ação que o fazer cultural pode ser trabalhado por meio de uma via de mão dupla, com trânsito assegurado à comunidade acadêmica, que encontrará, na sociedade, a oportunidade de elaboração da práxis do conhecimento acadêmico. No retorno à Universidade, docentes, discentes e técnico-administrativos 
envolvidos trarão um aprendizado que, submetido à reflexão teórica, será acrescido àquele conhecimento.

Vários são os incitamentos que nos convidam a persistir na ampliação do debate sobre cultura e gestão universitária no Brasil. Embora este tema já não seja incipiente em nosso país, certamente ele requer de resistência, dia após dia, para continuar a existir, especialmente, tendo em vista o cenário de crise política e ética enfrentado pelo país nestes últimos anos. Estratégias em rede são fundamentais para a democratização e acesso ao ensino superior no Brasil, e a temática da cultura tem papel fundamental no processo de escuta e ponte de diálogo potente entre universidade e sociedade.

Espera-se que os resultados desta pesquisa atuem como indicativos de novas possibilidades de criação de estratégias de ação na gestão cultural universitárias das IES públicas brasileiras. Que possamos ser testemunhas destes e de outros processos de transformação do ensino superior no nosso país, e que a cultura demonstre, cada vez mais, seu potencial de servir para a construção de uma práxis política comprometida com a transformação social.

\section{Agradecimentos}

A realização desta pesquisa contou com o apoio do Observatório Cultural Proyecto Atalaya, Universidade de Cádiz e Universidad Internacional de Andalucía, Espanha. Os agradecimentos se estendem, ainda, ao Fórum de Pró-Reitores de Extensão das Insituições Públicas de Educação Superior Brasileiras (FORPROEX) e à Universidade Estadual de Campinas (UNICAMP), na assessoria de pesquisa prestada por Malu Arruda e Cauê Mopesil.

\section{Referências}

ARRUDA, C. L. R. Profissão: artista: formação para a arte e sua relação com o ensino superior no Brasil. In: SEGNINI, L. R.P.; BULLONI, M. N. (org.). Trabalho artístico e técnico na indústria cultural [recurso eletrônico]. São Paulo: Itaú Cultural, 2016. p. 177194.

BARNABÉ, M. Cómo hablar de cultura en la universidad?: la gestión de un campo para los Estudios Culturales. Pragmatizes: Revista Latinoamericana de Estudos em Cultura. Rio de Janeiro, v. 2, p. 111-124, mar. 2012.

BARROS, J. M. Diversidade cultural e gestão: apontamentos preliminares. In: ENECULT ENCONTRO DE ESTUDOS MULTIDISCIPLINARES EM CULTURA, 4., 2008, Salvador. Anais [...]. Salvador: Centro de Estudos Multidisciplinares em Cultura da UFBA, 2008. 
BOTELHO, I. Cultura e universidade: reconstituindo as trajetórias dos diálogos institucionais. In: Políticas Culturais: Teoria e Práxis. São Paulo: Observatório Itaú Cultural, 2011, p. 96103.

CAUNE, J. Préface. In: LADORTUNE, J. M. (dir.). La médiation culturele: les sens des mots et l'essence des pratiques. Québec: Presses de l'Université du Québec, 2012.

CERRETI, C. C. Cultura, educação e políticas públicas para o ensino superior: um estudo propositivo do Programa Mais Cultura nas Universidades para os Estados da Bahia e Sergipe. 2014. Monografia (Curso de Formação de Gestores Culturais dos Estados do Nordeste) Instituto de Humanidades, Artes e Ciências Professor Milton Santos, Universidade Federal da Bahia, Salvador, 2014.

COSTA, P. M. D.; SANTOS, S. R. M.; GRISPUN, M. P. S. Z. Extensão universitária e o campo da política cultural. Meta: Avaliação, v. 1, n. 3, p. 352-368, set./dez. 2009.

FORPROEX, Fórum de Pró-Reitores de Extensão das Universidade Públicas Brasileiras. Política Nacional de Extensão Universitária. Manaus, 2012.

GOMES, E. E. O lugar da cultura na educação: desafios para a extensão universitária brasileira. Barbaquá, Cuiabá, v. 1, n. 1, p. 33-40, 2017.

GONZÁLEZ, M. A. J. et al. Políticas culturales para la educación superior en Colombia: ¡nuestro proyecto común! Medellín: Universidad de Antioquial, 2013.

INEP - Instituto Nacional de Estudos e Pesquisas Educacionais Anísio Teixeira. Microdados: Censo da Educação Superior 2015. Brasília, 2016.

LONDOÑO, A. G; GONZÁLEZ, M. A. J. (ed.). Universidad de Antioquia: culturas y camiños. Medellín: Universidad de Antioquia, 2006.

LÓPEZ BORBÓN, L. La gestión cultural como construcción de ciudadanía. México, DF, 2015.

LORENZONI, I. Censo mostra que ingresso de alunos cresceu 8,5\% em 2008. 2017. Disponível em: http://portal.mec.gov.br/component/tags/tag/32123. Acesso em: 23 abr. 2020.

NUNES JUNIOR, P. N. et al. Cultura y extensión universitaria en Brasil: un corredor de relatos. In: CONGRESSO ESPAÑOL DE SOCIOLOGÍA, 12., 2016, Gijón. Anales [...]. Gijón: Federación Espanhola de Sociología, 2016.

NUNES JUNIOR; P. N. Gestión cultural en instituciones públicas brasileñas de enseñanza superior: diagnóstico y posibilidades de acción en red. Universidad de Cádiz: Observatório Cultural Atalaya, n. 77, 2017.

RUBIM, A. A. C. Políticas culturais do governo Lula. Revista Lusófona de Estudos Culturais, v. 1, n. 1, 224-242, 2013.

RUBIM, A. A. C. Políticas culturais: entre o possível e o impossível. In: NUSSBAUMER, G. M. (org.). Teorias e políticas da cultura. Salvador: EDUFBA, 2007. 
SPELLER, P.; ROBL, F.; MENEGHEL, S. M. (org.). Desafios e perspectivas da educação superior brasileira para a próxima década. Brasília: UNESCO; MEC, 2012.

Submetido em 20 de fevereiro de 2020.

Aprovado em 10 de março de 2020. 